\title{
BMJ Open My life with lupus: contextual responses of African-American women with systemic lupus participating in a peer mentoring intervention to improve disease self-management
}

\author{
Trevor D Faith, ${ }^{1}$ Minnjuan Flournoy-Floyd,${ }^{2}$ Kasim Ortiz, ${ }^{3}$ Leonard E Egede, ${ }^{4}$ \\ $\operatorname{Jim}$ C Oates, ${ }^{5,6}$ Edith M Williams ${ }^{1}$
}

To cite: Faith TD, FlournoyFloyd M, Ortiz K, et al. My life with lupus: contextual responses of African-American women with systemic lupus participating in a peer mentoring intervention to improve disease self-management. BMJ Open 2018;8:e022701. doi:10.1136/ bmjopen-2018-022701

- Prepublication history for this paper is available online. To view these files, please visit the journal online (http://dx.doi. org/10.1136/bmjopen-2018022701).

Received 2 March 2018

Revised 21 May 2018

Accepted 5 September 2018

Check for updates

(c) Author(s) (or their employer(s)) 2018. Re-use permitted under CC BY-NC. No commercial re-use. See rights and permissions. Published by BMJ.

For numbered affiliations see end of article.

Correspondence to Dr Edith M Williams wiled@musc.edu

\section{ABSTRACT}

Objective The current article seeks to examine the ways in which African-American women with systemic lupus erythematosus (SLE) describe their disease experience and how they cope with their disease. This qualitative study provides deeper insight into whether experiences of African-American women with SLE differ from previous qualitative study findings.

Methods Qualitative data were gathered using interviews and a focus group, from participants in the Peer Approaches to Lupus Self-management (PALS) programme. Data were analysed for themes related to disease experience and how participants cope with their disease. Twenty-seven African-American women with SLE were recruited into the peer mentoring programme, of which 7 served as mentors and 20 served as mentees. A 12-week peer mentoring intervention delivered by phone and based on the Chronic Disease Self-Management and Arthritis Self-Management Programs.

Results Three categories encompassing a total of 10 subcategories emerged from analyses: (A) interpersonal, familialandromantic relationships; (B) individual experiences of living with SLE; and (C) physician-patient relationships.

Conclusion We gained insight on several issues related to patient perspectives of African-American women with SLE, and the context surrounding their thoughts and feelings related to lupus, including their providers, families and other social support networks. Additional research efforts could explore and address the thematic domains and respective subthemes identified here. Although limited due to the preliminary nature of the study, this information can be used to create future evidence-based interventions to decrease the impact of SLE on African-American patients.

\section{INTRODUCTION}

Systemic lupus erythematosus (SLE or lupus) is a chronic autoimmune disease that is associated with increased morbidity, mortality, healthcare costs and decreased quality of life. ${ }^{1}$ While evidence-based self-management interventions that incorporate both social support
Strengths and limitations of this study

- This article provides valuable contextual responses of African-American women with systemic lupus erythematosus (SLE) participating in a behavioural intervention that can be used to tailor care practices and other interventions.

- Data are synthesised from multiple sources in order to uniquely characterise these patients' disease experience.

- Data collection methods did not allow for follow-up on topics/concepts of interest, limiting the depth to which some could be explored and connected.

- The sample of patients with SLE represented in this study is, on average, of higher socioeconomic status and education level than the general patient population.

and health education have demonstrated ability to reduce pain, improve function and delay disability among lupus patients, ${ }^{2}$ African-Americans and women are still disproportionately impacted by lupus. ${ }^{3}$ In the USA, African-Americans have three to four times greater prevalence of lupus, risk of developing lupus at an earlier age and lupus-related disease activity, damage and mortality compared with Caucasians, with the highest rates experienced by African-American women. ${ }^{4}$ Persistent disparities have not been addressed by existing programmes that fail to meet the unique needs of African-Americans and/or women with lupus such as understanding the care regimen, communication and trust with care providers, having easily accessible support and knowing which symptoms should lead them to initiate a doctor's visit. $^{5-7}$

Quantitative studies assessing dimensions of psychosocial impact of SLE on 
the well-being of African-American women have been extremely important in developing potential clinical interventions to improve health-related quality of life among this population. For example, Mosely-Williams et $a l^{8}$ found that, compared with their white counterparts, African-American women were more likely to rely on religion for coping, and barriers to treatment adherence were more likely to be shaped and impacted by need for child or elder care. Williams et al demonstrated that self-management education, delivered in weekly sessions that incorporated peer support, led to improvements in lupus self-efficacy, health distress and depression in a cohort of African-American women with SLE. ${ }^{9-11}$

Many of these quantitative studies have focused on interventions that included trained educators who facilitate intervention progression. ${ }^{9}$ Peer mentoring interventions have previously been highly effective for improving chronic conditions that disproportionately affect minorities such as diabetes, HIV and kidney disease.$^{12}$ However, full integration of such interventions, aimed specifically at African-American women, are limited within SLE populations and research contexts. ${ }^{13-15}$ Additionally, quantitative studies focused on the impact of the peer mentoring approach on psychosocial dynamics have provided limited information about the psychosocial experiences of the minority populations under study. ${ }^{16}{ }^{17}$ Furthermore, knowledge uncovered from qualitative research can often provide much richer and deeper content that is not always as evident when using quantitative methods. ${ }^{1819}$

In a review of qualitative studies, Sutanto $e t a t^{20}$ highlighted experiences of those living with SLE. ${ }^{20}$ Five thematic areas were identified across the 46 studies included in their systematic review, inlcuding: (1) restricted lifestyle; (2) disrupted identity; (3) societal stigma and indifference; (4) gaining resilience; and (5) treatment adherence. ${ }^{20}$ Sutanto $e t a l$ s systematic review highlights the difficulties experienced by those suffering from SLE in the USA but did not parse findings based on race/ethnicity. Since African-American women constitute the largest proportion of the general US population diagnosed with SLE, and recognising their higher rates of mortality and diminished physical and mental health functioning as a result of lupus-related disease activity, understanding the psychosocial experiences of SLE within this population is warranted. This knowledge can then be used to better culturally tailor interventions and address the unique needs of this vulnerable population.

The current study seeks to address an important gap in the literature by highlighting the ways African-American women with SLE describe their disease experience. This qualitative study provides deeper insight into whether experiences of African-American women with SLE differ from previous qualitative study findings; specifically, we use Sutanto $e t a l$ s study as a guide in identifying convergence and potential divergence. ${ }^{20}$ To achieve our objectives, this study draws on a multimethod qualitative approach where data from a longitudinal peer mentoring intervention is analysed. ${ }^{21}$

\section{METHODS}

The Peer Approaches to Lupus Self-Management (PALS) study was a single-arm, pre-post pilot in which 30 African-American women with lupus were recruited from the Medical University of South Carolina (MUSC) P60 MCRC longitudinal SLE cohort who consented to contact about research and through physician referral (10 mentors and 20 mentees). The 12-week peer mentoring intervention sought to produce preliminary data on the effectiveness of peer mentoring among African-American women with SLE with regard to disease self-management, health-related quality of life and disease activity. ${ }^{21}$ As part of the study, weekly qualitative interviews and a postintervention focus group were conducted to assess progress, garner feedback and capture the contextual experiences of African-American women with SLE that could be used to refine and further culturally tailor the intervention.

\section{Patients}

All patients participating in the current study met diagnostic criteria for SLE based on the revised American College of Rheumatology criteria and provided written informed consent at the time of their enrolment. ${ }^{22}{ }^{23}$ PALS was a telephone-based peer mentoring intervention, recognising that previous research has identified travel-related barriers for patients with SLE, ${ }^{245}$ especially in South Carolina where the study was conducted.

\section{Recruitment}

Research participants were not known by the investigator prior to the study. Peer mentors were identified in a two-tier process. First, potential mentors were extracted from the MUSC P60 MCRC longitudinal SLE database where rheumatologists and other clinicians identified patients deemed highly competent about SLE. Second, the principal investigator (PI) mailed recruitment letters and those who responded were interviewed to assess maturity, emotional stability and verbal communication skills. The interview included questions from the psychological scales of the Arthritis Impact Measurement Scales, the Arthritis Helplessness Index, Wallston General Perceived Competence Scale, University of California at Los Angeles Loneliness Scale, Rosenberg Self-Esteem, Campbell Personal Competence Index, Carkhuff Communication and Discrimination Skills Inventories and the Applied Knowledge Assessment scale. ${ }^{26-32}$

Mentees were also recruited using direct mailings, flyers and physician referral. The target was 10 mentors and 30 mentees to have a 1:3 mentor-to-mentee ratio. Letters were mailed to 450 potential mentees and 24 potential mentors. Additionally, recruitment flyers were placed in MUSC lupus clinics. In the 1-month recruitment period, 23 potential mentees responded, but 3 later withdrew from the study, and 18 potential mentors responded, but 3 were deemed ineligible to participate, 1 withdrew and 2 wished to serve as alternates. The resulting study population included 20 mentees and 7 mentors leading to a 1:3 ratio in six groups, and a 1:2 ratio in 1 group. As part 
of eligibility screening, potential mentees completed an assessment of self-efficacy and were then scheduled for their baseline visit and initiation of the intervention. A detailed description of eligibility and selection criteria is reported elsewhere. ${ }^{33}$ During the informed consent process, prior to study procedures, participants were informed of the purpose of the research and intentions of the researchers to develop a programme to benefit African-American women with SLE.

\section{Data collection}

A two-tiered approach for capturing qualitative data was used. Specifically, we implemented both interviews between an experienced female African-American study coordinator and mentees throughout the course of the study and a focus group that included both mentees and mentors at the end of the study. For the purpose of validating perspectives, our data had a 'multilevel' framework insofar as we were able to capture both individual-level and group-level data. ${ }^{34-37}$

Interviews between the PALS study coordinator and mentees were conducted by phone weekly. These interviews took approximately $10 \mathrm{~min}$ and covered the length and content of interactions between mentors and mentees to ensure intervention adherence and satisfaction. Peer mentors also kept a log of their weekly sessions with their mentees, and the PI held face-to-face meetings with mentors once per week to address potential adverse events.

The focus group was held at the end of the study and was conducted and audio-recorded by the PI (EMW, African-American female, $\mathrm{PhD}$, previous experience as phone interviewer and several years experience conducting community-based participatory research) and research assistant (TDF, white male, BS, 1 year of research experience, Human Subjects and Core Clinical Research Certified) at the offices of MUSC's Department of Public Health Sciences to debrief participants and to capture qualitative feedback on the study. We sought to produce an opportunity for group iteration to assess whether individual perspectives related to the intervention were also present within group dynamics. Combining both individual-level and group-level responses for convergence produces greater validity in our findings. Fifteen participants were able to attend the 1.5-hour focus group arm of the study, while others were unable to attend due to prior commitments and travel issues. The focus group participants responded to semistructured questions that were not provided prior to the session. Thus, data for the current study were captured in three formats: (1) mentor logs, (2) mentee check-in interviews and (3) combined mentor/mentee focus group. Logs were kept by the study mentors weekly and captured their perspective on the interactions that took place between themselves and their mentors. Their logs included a journal section that characterised this unique perspective and can elucidate any longitudinal changes in the mentees' attitudes, thoughts and concerns that occurred over the course of the study.
Mentors' journal entries reflect the answers mentees gave to questions designed to encourage reflection on weekly content and general discussion of coping and disease management practices. Mentors submitted logs to the PI on a weekly basis and were transcribed by study staff and entered into an ongoing data file. All logs were considered in qualitative data analysis.

\section{Data analysis}

Sutanto $e t a l^{20}$ identified a mixture of grounded theory, and the use of phenomenological approaches as conceptual guides, as common methods employed by qualitative studies seeking to highlight psychosocial experiences of those with SLE. ${ }^{20}$ It is important to note that phenomenology and grounded theory may not have been the best fit to examine the qualitative responses in this study, although the study topic is the same. In reviewing appropriate analytical methods, the researchers determined that thematic analysis is the better fit for this study. The focus of thematic analysis is on analysing narrative elements of life experiences and accounts. ${ }^{38}$ Thematic analysis is flexible enough to allow for a rich, detailed and complex contextual account for the data. Thematic analysis involves the search and identification of common threads that extend across an entire interview or set of interviews. $^{39} 40$

Audio recording were transcribed by the research assistant (TDF) and spot checked by the PI (EMW). To analyse the data collected, we used NVivo 10.1 software. $^{41}$ Initially, a thematic codebook was developed to facilitate identification of themes that might converge and/ or diverge from those identified within Sutanto et als guiding paper. ${ }^{20}$ The thematic codebook was developed by two trained qualitative researchers independently and then combined, wherein reconciliation occurred if any themes identified individually differed. This process of cyclical thematic codebook development has been shown to improve precision in the identification of particularly salient themes among participants within qualitative studies. ${ }^{38} 3942$ As a result of the longitudinal nature of the intervention, the thematic codebook also allowed for multiple coverages of possible topics. Major themes were defined as those that represented more than $50 \%$ of the responses in the weekly mentor logs and/or opinions voiced by more than $50 \%$ of mentees. While the current study's findings are presented as a snapshot, the longitudinal nature of the data facilitated greater ability to ensure sufficient saturation during analyses, increasing our validity in terms of findings.

\section{Patient involvement}

The PALS intervention has adhered to the five accepted stages of cultural adaptation ${ }^{43}$ : information gathering was achieved through extensive literature review and ascertainment of patient and participant feedback, ${ }^{14} 44-47$ while preliminary design built on lessons learned from prior behavioural interventions in the same patient population. ${ }^{45}$ The remaining stages are covered in the 
Table 1 Sociodemographic characteristics of mentees and mentors participating in the PALS intervention

\begin{tabular}{|c|c|c|c|}
\hline \multirow{2}{*}{ Variable } & & \multicolumn{2}{|c|}{ Designation (\%) } \\
\hline & & $\begin{array}{l}\text { Mentee } \\
\mathrm{n}=23\end{array}$ & $\begin{array}{l}\text { Mentor } \\
\mathrm{n}=10\end{array}$ \\
\hline \multirow[t]{6}{*}{ Age (years) } & $<25$ & $2(8.7)$ & $0(0.0)$ \\
\hline & $25-34$ & $2(8.7)$ & $3(30.0)$ \\
\hline & $35-44$ & $8(34.8)$ & $3(30.0)$ \\
\hline & $45-54$ & $5(21.7)$ & $1(10.0)$ \\
\hline & $55-64$ & $1(4.4)$ & $2(20.0)$ \\
\hline & $>65$ & $5(21.7)$ & $1(10.0)$ \\
\hline \multirow[t]{2}{*}{ Married } & Married & $2(8.7)$ & $3(30.0)$ \\
\hline & Other & $21(91.3)$ & $7(70.0)$ \\
\hline \multirow[t]{4}{*}{ Education } & $\begin{array}{l}\text { Less than high } \\
\text { school }\end{array}$ & $3(13.7)$ & $0(0.0)$ \\
\hline & $\begin{array}{l}\text { High school } \\
\text { graduate }\end{array}$ & $2(9.1)$ & $0(0.0)$ \\
\hline & Some college & $3(13.7)$ & $2(20.0)$ \\
\hline & College graduate & $14(63.6)$ & $8(80.0)$ \\
\hline \multirow[t]{5}{*}{ Income } & Below $\$ 14999$ & $5(21.7)$ & $0(0.0)$ \\
\hline & $\$ 15000-\$ 34999$ & $6(26.1)$ & $3(33.3)$ \\
\hline & $\$ 35000-\$ 64999$ & $5(21.7)$ & $1(11.1)$ \\
\hline & $\geq \$ 65000$ & $2(8.7)$ & $4(44.4)$ \\
\hline & $\begin{array}{l}\text { Other/don't want to } \\
\text { respond }\end{array}$ & $5(21.7)$ & $1(11.1)$ \\
\hline
\end{tabular}

PALS, Peer Approaches to Lupus Self-Management.

refinement of this protocol for a full-scale randomised trial. Moreover, a community advisor and member of the Lupus Foundation of America was used to develop and tailor the protocol to the needs of this population. Patients played a vital role in the delivery of this intervention as mentors were trained patients.

\section{RESULTS}

Table 1 provides demographic characteristics of both mentors and mentees. Eight of the mentors were aged $35-44$ years $(34.8 \%)$, while $30 \%$ of the mentees were in the same age group $(n=3)$. Both mentors and mentees were mostly unmarried. The majority of mentees $(n=14)$ reported annual household incomes between $\$ 15000$ and $\$ 34,999$, while the majority of mentors $(n=4)$ reported annual household incomes of $\geq \$ 65000$. Also, the majority of both mentees $(n=14)$ and mentors $(n=8)$ reported having graduated college.

Three categories encompassing a total of 10 subcategories emerged from qualitative data analysis: (A) interpersonal, familial and romantic relationships; (B) individual experiences of living with SLE; and (C) physician-patient relationships. An additional category of "characteristics of mentor/mentee relationships' emerged but was separated from the other nodes due to its distinction from responses that illustrated the cultural context of mentees participating in the study. We report only mentee responses that could be viewed as representative of the mentee perspective. Again, we used the weekly phone interviews to collect individual-level data and the focus group as a means of capturing group-level data and verifying findings from phone interviews.

\section{Interpersonal, familial and romantic relationships}

A major theme, throughout the intervention, that was highlighted by mentees was the impact of SLE on interpersonal, familial and romantic relationships. Major findings for this thematic area, and corresponding subcategories, can be found in table 2. Findings highlighting the impact on interpersonal relationships, among African-American women who are living with SLE, included difficulty with physical contact leading to pain. For example, a firm handshake could lead to throbbing pain in a lupus patient's hands. Additionally, hugging was a factor that was discussed as having an impact on interpersonal relationships. One mentee described her experiences with hugging her pastor and other parishioners at her church. She recalled discussing with her church's deacon that hugging posed a problem because her immune system was compromised due to her lupus, and she, more easily than others, caught colds from simply hugging individuals who had colds at church.

Familial relationships, or the impact of SLE on familial relationships, were also discussed consistently among participants. For example, one mentor described how fortunate she was to have family who took initiative to become educated about lupus and how understanding the disease has helped them support her in managing the symptoms of the disease. One mentee recalled that her family observed her cues of not feeling well by allowing her to go to her quiet place; they would allow her some quiet, private time. While the participant wanted this, she also wanted more interaction with her family, at the same time, thus, finding it difficult to negotiate the amount of engagement and interaction she wanted and/or needed with her family when she was experiencing a flare.

Lastly, in this thematic area, the impact of SLE on romantic relationships was discussed by several participants. One mentee discussed how it could be challenging to feel well enough or motivated to get dressed to go out on dates. Participants also discussed negotiating and explaining lupus to their husbands or boyfriends, and how the pain associated with their illness interfered with the desire for the slightest touch or intimacy and made it difficult to explain that their momentary 'rejection' was not personal.

In summation of this thematic area, it is important to note that physical touch, no matter the type of relationship, oftentimes unintentionally initiated pain in our participants. Although not directly related to interpersonal relationships, the idea of pain being a controlling aspect of the disease arose as part of these findings. 
Table 2 Qualitative findings, summary of findings for interpersonal, familial and romantic relationships thematic domains (mentees)

\section{Subcategory Excerpts}

Interpersonal 'I have problems with the handshake also. 9 time[s] out of $10 \ldots$ I hug them softly so they can also hug me relationships lightly, and with the handshake I say well could you shake my hand softly, don't make it hard. And they say "well what's wrong with you?" I went "well my hands hurt sometimes so if you grab it real hard it gonna start hurting and start throbbing me. Let's lightly shake and we lightly shake hands or don't at all."'

'Like in my church I talked to my deacon because people used to hug me all the time and I used to get sick all the time. Like if someone had a cold l'd get sick all the time. So I talked to my deacon, so they stopped doing the hugging in the church now for me. *Someone else: people get offended ${ }^{\star}$ yeah well my deacon and the preacher now we don't do hugging in the church anymore. So I let them know because I get real sick real easy, my immune system is kinda low. If they have a cold they gonna like kiss you on the face uh mmm (negative gesture) so that [is] why they did this for me at my church.'

'... then I feel, if somebody touches my hand the wrong way or touch me the wrong way, I'm like that hurts and my hardest thing is when somebody shakes your hand in church. But that's the hardest thing for me because they'll come and shake my hand and I'm like, if I back away they're like "oh you're being selfish". They don't know how I feel. How many other people have that same problem I have?'

Familial 'My husband and my daughter know when I don't feel good, everything stops. They say ok you go to your Relationships quiet spot and we'll leave you alone. I think that helps a whole lot, and then sometimes again I'm like, I want them to talk to me, I want them to come hug me...'

'For us, when we're sitting here 9 time[s] out of 10 most of us have family to support... Our families were intelligent enough to become knowledgeable about lupus and knowledgeable about our situations. We're the lucky ones, there's [sic] some folks out there that have been diagnosed, they don't have that. They don't even have the ability to find out the information for themselves, they don't even have the resources of having a family that's willing to do that part.'

'I don't know how it is for everybody, but I mean there's time with my lupus, I can't even have my kids touch me."

\begin{tabular}{|c|c|}
\hline \multirow[t]{3}{*}{$\begin{array}{l}\text { Romantic } \\
\text { relationships }\end{array}$} & $\begin{array}{l}\text { '[Negotiating with others] With your spouse too, and how they feel about you having lupus. Sometimes you } \\
\text { aren't in the mood to... you know... and sometimes you're tired and don't wanna get dressed and go out. So I } \\
\text { guess... if you stop to understand that it won't be an issue, you being intimate with your partner.' }\end{array}$ \\
\hline & $\begin{array}{l}\text { 'So it does create problems, I date, and sometimes I just have to tell my boyfriend, don't come near me. It's } \\
\text { nothing wrong with you, it's just this is one of these time[s] where you just can't touch me, not a hug don't } \\
\text { touch my shoulder, don't even accidently bump into me. Because it is that bad.' }\end{array}$ \\
\hline & $\begin{array}{l}\text { '... I think it was good to talk about it because it does affect your relationship when you have lupus. It's } \\
\text { something that does affect the younger people, like me, I'm young, l'm in a relationship, it didn't affect my } \\
\text { relationship with the guy l'm dating but I think the older people probably...' }\end{array}$ \\
\hline
\end{tabular}

\section{Individual experiences of living with SLE}

Another major thematic area that emerged centred on mentees' experiences of living with SLE (see table 3) and included the following subcategories: (A) faith; (B) disease functioning and acceptance; and $(\mathrm{C})$ pain and fatigue.

Participants discussed their faith and religious beliefs at length, as it relates to lupus. They expounded on their belief in and relationship with God, belief in healing and how these thoughts and practices help them remain compliant to their medical regimens and cope with SLE. They discussed refocusing their energy and thoughts on God and the Word (Biblical scriptures) rather than their symptoms associated with lupus.

Patients also discussed how they have had to make adjustments to their daily work functions since having been diagnosed with SLE and accepting their diagnosis. Furthermore, they described that on some days they are normally physically capable, whereas on other days, they can do very little or nothing at all. Regardless of how much or how little they can do, they have accepted that this is life and that functionality is variable day to day.

\section{Physician-patient relationships}

Patient-physician relationships (see table 4) were a thematic area that arose multiple times during the intervention. The major subcategories that emerged from those responses included: (A) familial relationships with physician care and (B) empathy among physicians. Patients discussed the roles that their family members assumed in following up with physicians to ensure that the patients were diagnosed correctly and received the follow-up care they needed.

Additionally, participants highlighted the need for employees working in provider offices, especially direct care staff, to have a more empathetic presence and understanding of the challenges associated with having lupus. Participants noted that this includes the clinical challenges, as well as the social and diminished quality 
Table 3 Qualitative findings and summary of findings for experiences of living with SLE by mentees thematic domain

\begin{tabular}{|c|c|}
\hline Subcategory & Excerpts \\
\hline \multirow[t]{3}{*}{ Faith } & $\begin{array}{l}\text { 'I'd say if you don't claim it you don't have it. That's how I believe in God, you don't claim it, you don't have } \\
\text { a disease. I haven't had a flare in I don't know how long. I don't claim that I have lupus at all. I mean I know } \\
\text { the side effects and everything that goes on with your body but like I said I don't claim it and I feel fine, I } \\
\text { mean I get sick but like I said I don't... I don't claim in. I still go to the doctor and take my medicine and do } \\
\text { what I need to do but it's God.' }\end{array}$ \\
\hline & $\begin{array}{l}\text { 'So I believe in the power of the Word (biblical scriptures) really helps [sic], instead of tensing up, learn } \\
\text { to relax, instead of having your mindset on what's wrong with your body, tell your body it's not there and } \\
\text { meditate in the Word. Just trying to thinking on healthy thoughts instead of sickness thoughts. It is, if I say } \\
\text { I'm sick, I'm gonna be sick, if I change it and say I'm not gonna be sick and believe what the Word says and } \\
\text { see what the Word says, then the Word it [is] powerful enough to bring on whatever it says.' }\end{array}$ \\
\hline & $\begin{array}{l}\text { 'I had to realize, I got to change my attitude, and say thank you God for bringing this life, whatever you have } \\
\text { for me, let me be able to helm it, in your name and the mental battle in our mind about leaving.' }\end{array}$ \\
\hline \multirow[t]{2}{*}{$\begin{array}{l}\text { Disease } \\
\text { functioning and } \\
\text { acceptance }\end{array}$} & $\begin{array}{l}\text { 'You know when I first got diagnosed with lupus, I got angry because I couldn't do what I wanted to do } \\
\text { anymore. I couldn't work anymore, I get to work and get out of the car and...? ... I get angry at myself and } \\
\text { the world because I have to stop my job at age } 49 \text { because I can't work anymore. Because I get to work, I } \\
\text { can't do my job.' }\end{array}$ \\
\hline & $\begin{array}{l}\text { 'I needed to accept that I have lupus and I need to slow down, and it was ok for me to say, tell my family } \\
\text { "no". Even sometimes just taking a day, and it was ok to lay in bed and just hurt. Because in my mind } \\
\text { it was... I'd have a really bad day and when the next day comes and it's a good day I'm out retiling a } \\
\text { bathroom, cooking, working in the garden, taking } 2 \text { and } 3 \text { mile hikes when I should just take it easy and do it } \\
\text { in moderation. I think that's the biggest thing, it taught me moderation and it's not something I'm just gonna } \\
\text { have to... you know you have to take the pain day by day but you don't have to take life day by day. You can } \\
\text { do it all in moderation and keep a consistency instead of such highs and lows.' }\end{array}$ \\
\hline \multirow[t]{2}{*}{ Pain and fatigue } & $\begin{array}{l}\text { '... [l]f you get close to me l'm in pain. Don't touch my hands my arms, nothing... don't come near me. It's } \\
\text { nothing wrong with you, it's just this is one of these time where you just can't touch me, not a hug don't } \\
\text { touch my shoulder, don't even accidently bump into me.' }\end{array}$ \\
\hline & $\begin{array}{l}\text { '... explain to the doctor this is where the joint pain is, it hurts when I turn, it hurts when I get up.' } \\
\text { '... I['ve] had it for sixteen years, I had to learn how to cope with some of my pain. Sometimes I take a bath, } \\
\text { sometimes I go walking, relaxing, it goes away.' }\end{array}$ \\
\hline
\end{tabular}

of life-related challenges that come with managing the effects of lupus.

An overarching theme throughout the responses of our cohort of African-American women with SLE was pain. Our participants described pain as discussed with their providers, as well as how they explain the pain they experience to family, loved ones and those in their social networks.

\section{Mentor logs: longitudinal insight}

Table 5 helps to synthesise some of these themes while providing additional insights into the struggles and unique experiences African-American women with SLE face. The table contains excerpts from the mentors' journal logs that show some of the changes that occurred in mentees during the study but also indicates concerns and themes that were persistent throughout. Selected excerpts from weeks 1 and 2 as well as the first entry from week 4 highlight the hardships mentees faced early on in the study, such as the uncertainty and lack of control patients experience after diagnosis, difficulties coming to terms with the physical limitations SLE can impose and associated isolation. However, the tone of the journal

Table 4 Qualitative findings and summary of findings for patient-physician relationships thematic domain (mentors)

Subcategory Excerpts

Familial relationships ‘.... when I was at my sickest I couldn't advocate for me [sic], I was lucky I had a dad who cared and physician care enough when my baby was born her took me to the doctor and said "this is not her, something is wrong and I'm not leaving until I get some answers. So if it weren't for my dad I probably would've... who knew what would have happen[ed]?" ,

Physician, and related '[A]lright let me tell you what's gonna happen, my momma doesn't work on Mondays, so you're gonna healthcare personnel, make an appointment on Monday and your gonna start it but l'm gonna finish it at such and such empathy time'. That wouldn't have been a problem for me caring but we were trained not to cross that line so that was a thing for me. However, if physician offices had people working that cared and understood how this disease impacts us the interactions would be different.' 
Table 5 Selected responses from mentor journals: open-ended responses given based on questions pertaining to weekly intervention content and interactions with their mentee

\begin{tabular}{|c|c|c|}
\hline Week & Question & Excerpts \\
\hline 1 & $\begin{array}{l}\text { What comes to mind when you think about your } \\
\text { life and living with lupus? }\end{array}$ & 'Uncertainty' \\
\hline 2 & $\begin{array}{l}\text { What ways can you pace yourself to do the } \\
\text { activities that you would like to do? }\end{array}$ & $\begin{array}{l}\text { 'Can lower the amount of events on her calendar that she } \\
\text { participates in. Does not do well with slowing down. *this seems } \\
\text { to be the biggest and hardest lesson between all my mentees and } \\
\text { myself*' }\end{array}$ \\
\hline 3 & $\begin{array}{l}\text { How do you feel about having to try a new } \\
\text { prescribed medication? }\end{array}$ & $\begin{array}{l}\text { 'Not her thing. She stated that she has a little chip on her } \\
\text { shoulders about doctors. Does not like brand new medicine- does } \\
\text { not want to be an experiment.' }\end{array}$ \\
\hline
\end{tabular}

$4 \quad$ Do you talk with others about your lupus? If so, do you mind sharing what kinds of things are discussed? If not, why not?

Note: not a response to a specific question.

'With family she does not talk about it much because she feels they don't understand. It can be frustrating.'

'As the weeks are going by, I can hear a change in [mentee's name]. She is becoming more open and she seems willing to try different things. [Mentee] even stated that she is going to have to talk with her boyfriend and daughter about lupus and try to understand just how much they know about. Talking about her illness has been a big issue with [mentee], because she does not like pity, but she is realizing that for people around her to understand what she is going through, she needs to be open about it and be willing to talk to others.'

$6 \quad$ How do you handle flare-ups when they happen? 'Not sure. It depends on the severity (she is very anti-meds). Honestly is not sure when she is having a flare-up. Asked what a flare-up is. Made statement that doctors do not really go into details about flare-ups and what to look for.'

$8 \quad$ Do you think you can try to think past what the

'Yes. Feels better than before. Feels like she has more control side effects are and internalise some positives? because she can adjust and learn to pace herself.'

$9 \quad$ Do you think you can try some of the coping techniques we talked about in earlier sessions to help you better deal with lupus complications that may arise?

11 Note: not in response to a specific question.

'Yes- get back in routine of walking again. Feels better emotionally and physically.'

'She does not [let] lupus hold her back from having relationships. The rest of the conversation was spent with her giving me encouragement to not let lupus stop me from having a relationship. This session was kind of the hardest for me because I have not been in a relationship or have had any intimacy for 13 years. She said I should not let lupus control my love life.'

12 Do you plan to share your experience with others? Using the skills that you have learnt, what do you plan to do next time you experience a flare up?

\section{and has helped her talk more about her lupus.'}

'Still needs to know what exactly a flare up is and how it would be for her (she is going to question her rheumatologist about it).' entries changed as the study progressed, as exemplified by the inclusions from weeks 8,9 and the first entry from week 12. These reflections show that as the intervention progressed, participants began to gain a sense of control over their disease and symptoms, set goals to achieve better well-being and be more open and communicative about their disease.

These subjective improvements are validated by two notes mentors left in their journals in weeks 4 and 11 . The note from week 4 indicates a turning point for one mentee that is due, in part, to the social support and skills the intervention encouraged. The note from week 11 describes the mentees' growing confidence that helped to foster a reciprocal support relationship from which both mentors and mentees could benefit.

One persistent concern expressed throughout the journals related to mentee's relationships with their doctors. While some individuals expressed satisfaction, excerpts from weeks 3, 6 and the second from 12 reflect a more prevailing concern. Week 3 exemplifies an attitude of mistrust towards physicians and is substantiated by the remaining two entries. Synthesising these responses along with the previously observed concerns about provider empathy further illustrates issues within 
the patient-provider relationship. There is a lack of empathy on the part of the provider, and this appears to be compounded by a lack of trust and poor communication on the part of the patient, resulting in unfavourable attitudes towards their physicians and medications.

\section{Discussion}

In this study, we gained insight on several issues related to the patient perspectives of African-American women with SLE and the context surrounding their thoughts and feelings related to lupus, including their providers, families and other social support networks. Pain associated with SLE was a topic that was interwoven throughout the conversations. We learnt about how PALS participants felt about the relationships they had with providers, and how they navigate care and advocacy (sometimes with the assistance from family members). We also gained perspective on the intervention itself from mentored participants, regarding phone call dynamics and future suggestions. The pain associated with SLE was discussed by several participants in different contexts. This was consistent with other studies that have highlighted pain as a major concern in the everyday experiences of patients with SLE. ${ }^{13} 4849$ However, our cohort comprised entirely of African-American women, offered unique insights into how they cope with their pain and disease experience overall, which reiterates the need for culturally relevant management and coping techniques to confer improvements to health-related quality of life in this population.

Mentees also described difficulty in negotiating appropriate levels of engagement in interpersonal, familial or romantic relationships, along the lines of physical and emotional support from their social networks. Sutanto et al (2013) highlighted disease impacts on familial relationships for patients with SLE, particularly in relation to whether patients felt a lack of independence resulting from family members being too overprotective and intrusive when obtaining rheumatological care. ${ }^{20}$ In contrast, PALS participants shared positive observations of the role of their families in their care. Family members served as true patient advocates, placing their loved ones' care as priority, which suggests that this may be warranted as an area of focus in future interventions tailored to the context and needs of African-Americans with SLE. Sutanto ${ }^{20}$ also found in her work that empowerment and control were recurring themes among the patients with SLE she studied. Similarly, patients in the PALS intervention touted the value of being in control of their disease, and while their methods varied from relying on religion, social support networks, to personal advocacy and self-care, this recurring theme reinforces the value of interventions seeking to influence self-management and self-efficacy. Lastly, in his qualitative research, Karlen ${ }^{50}$ observed that women living with SLE most often experienced disruption in positive sexual lives. However, responses from African-American women with SLE participating in our study extend Karlen's findings to include the impact of pain on intimate desires.
The feedback from PALS participants yielded rich contextual information that can be used to create future evidence-based interventions to decrease the impact of SLE on African-American patients. Additional research efforts could specifically explore and address the thematic domains and respective subthemes that we have identified. There were specific concerns shared regarding provider care and the need for empathy and improved communication from providers and medical support staff. This was a cross-cutting theme that also appeared in patients' perspectives of their familial relationships. This indicates a need for more education and possibly interventions targeted towards improving the sensitivity and cultural awareness of providers and office staff to meet the clinical and empathetic needs of this population. Employing such methods could address the mistrust our participants expressed towards physicians as well, according to findings from Sutanto's work. In her review, Sutanto found that effective communication and understanding displayed by physicians resulted in improvements to the doctor-patient relationship (ie, trust and respect) and could improve medication adherence among patients as a way of showing their appreciation towards their physician. ${ }^{20}$ Furthermore, extending this education to the families and friends of patients with SLE could increase the overall empathy they experience and confer benefit to their social support networks.

While struggles mentioned in logs are consistent with several studies of how SLE, regardless of ethnicity, initiates uncertainty, lack of understanding from peers, learning to control and pace over time and so on, themes also aligned with unmet needs that have been disproportionately reported by African-Americans with SLE. ${ }^{5-7}$ Previous results have shown that African-American patients with SLE were more likely than white patients to have higher levels of unmet needs related to health services and information. ${ }^{6} 751$ These domains have included issues such as: (1) understanding the medical regimen, including considerations around depression, medication concerns (possible side effects and interactions) and physical symptoms (pain and fatigue), (2) trust in the provider, (3) communication with providers, (4) receiving adequate information from medical staff about treatment side effects, (5) having access to telephone support and advisory services and (6) having assistance with knowing which symptoms should trigger a doctor visit. ${ }^{6}$ Such deficits are compounded by findings that doctors may not be skilled in determining their needs and the barriers that lupus patients experience, ${ }^{52}$ which may preclude adequate disease management ${ }^{8}$ and contribute to persistent disparities.

There are a few limitations to note regarding this study. While interview and focus group questions were openended, there was no protocol to follow up with probing in order to clarify or delve further into initial responses. This inability to follow up on specific responses does not allow the researcher to connect thoughts that are sometimes disjointed or incomplete. However, the peer mentoring 
programme that this qualitative investigation was nested within aimed to impact and assess the disease experience and quality of life of African-American women with SLE who participated, so any and all participant responses were valid reflections of their experiences. Additionally, although not explicitly captured in this study, there may be a unique cultural experience common to our study participants as a result of being more highly educated African-American women with SLE living in the area of Charleston, South Carolina.

\section{CONCLUSION}

Despite limitations, the results of this study provide important and foundational qualitative data that will be beneficial for generating hypotheses for future studies, including considerations of social networks, interactions with caregivers and providers and SLE interventions using a peer mentoring approach. Key themes that described important issues surrounding SLE impact on African-American women could be useful for rheumatologists and other providers who care for patients with SLE, as well as SLE patient navigators, those who support or provide daily care for persons with lupus and persons who have lupus themselves. A better understanding of how African-American women cope with SLE and the context within which they make disease-related decisions could provide important sbenchmarks for improving coping, management, and care services and strategies.

\section{Author affiliations}

${ }^{1}$ Department of Public Health Sciences, Medical University of South Carolina, Charleston, South Carolina, USA

${ }^{2}$ Center for Substance Abuse Treatment, Substance Abuse and Mental Health Services Administration, Rockville, Maryland, USA

${ }^{3}$ Department of Sociology, University of New Mexico, Albuquerque, New Mexico, USA

${ }^{4}$ Department of Medicine, Medical College of Wisconsin, Milwaukee, Wisconsin, USA ${ }^{5}$ Division of Rheumatology and Immunology, Medical University of South Carolina, Charleston, South Carolina, USA

${ }^{6}$ Rheumatology Section, Ralph H. Johnson VA Medical Center, Charleston, South Carolina, USA

Acknowledgements We would like to acknowledge the participants of this study who provided their personal stories and experiences with lupus. We would also like to thank the study coordinator Vernessa Nelson for her dedication to the project and assistance with data collection as well as Hetlena Johnson for her assistance in developing the methodology and tailoring the intervention.

Contributors TDF made contributions to the concept and design of the work, acquisition and interpretation of data and drafted the manuscript. MF-F and KO contributed to the analysis and interpretation of the data and assisted with the drafting of the manuscript. LEE and JCO provided substantial contributions to the conceptual design of the work and revised draft of the manuscript. EMW provided substantial contributions to the design of the work, acquisition and interpretation of the data and revisions to the manuscript drafts. All authors read and approved of the final version of this work and agree to be accountable for their respects aspects therein.

Funding This project was supported by the South Carolina Clinical \& Translational Research (SCTR) Institute, with an academic home at the Medical University of South Carolina CTSA, NIH/NCATS Grant Number UL1 TR001450, the Rheumatology and Immunology MCRC NIH/NIAMS Grant Number AR062755, NIH/NIAMS K23 AR052364 and NIH/NCRR UL1 RR029882.
Disclaimer The contents are solely the responsibility of the authors and do not necessarily represent the official views of the NIH, NIAMS, or NCATS. Funding sources had no role in study design; in the collection, analysis and/or interpretation of data; in the writing of the manuscript; or the decision to submit the article for publication.

Competing interests None declared.

Patient consent Obtained.

Ethics approval MUSC IRB.

Provenance and peer review Not commissioned; externally peer reviewed.

Data sharing statement Data can be made available upon request to the corresponding author.

Open access This is an open access article distributed in accordance with the Creative Commons Attribution Non Commercial (CC BY-NC 4.0) license, which permits others to distribute, remix, adapt, build upon this work non-commercially, and license their derivative works on different terms, provided the original work is properly cited, appropriate credit is given, any changes made indicated, and the use is non-commercial. See: http://creativecommons.org/licenses/by-nc/4.0/.

\section{REFERENCES}

1. Rahman A, Isenberg DA. Systemic lupus erythematosus. $N$ Engl J Med 2008;358:929-39.

2. Lorig K, Ritter PL, Plant K. A disease-specific self-help program compared with a generalized chronic disease self-help program for arthritis patients. Arthritis Rheum 2005;53:950-7.

3. Fernández M, Alarcón GS, Calvo-Alén J, et al. LUMINA Study Group. A multiethnic, multicenter cohort of patients with systemic lupus erythematosus (SLE) as a model for the study of ethnic disparities in SLE. Arthritis Rheum 2007;57:576-84.

4. Pons-Estel GJ, Alarcón GS, Scofield L, Reinlib L, Cooper GS, et al. eds. Understanding the epidemiology and progression of systemic lupus erythematosus. Seminars in Arthritis and Rheumatism: Elsevier, 2010.

5. Hootman JM, Helmick CG. Projections of US prevalence of arthritis and associated activity limitations. Arthritis Rheum 2006;54:226-9.

6. Danoff-Burg S, Friedberg F. Unmet needs of patients with systemic lupus erythematosus. Behav Med 2009;35:5-13.

7. Feldman $\mathrm{CH}$, Bermas $\mathrm{BL}$, Zibit M, et al. Designing an intervention for women with systemic lupus erythematosus from medically underserved areas to improve care: a qualitative study. Lupus 2013;22:52-62

8. Mosley-Williams A, Lumley MA, Gillis M, et al. Barriers to treatment adherence among African American and white women with systemic lupus erythematosus. Arthritis Rheum 2002;47:630-8.

9. Williams EM, Penfield M, Kamen D, et al. An intervention to reduce psychosocial and biological indicators of stress in african american lupus patients: the balancing lupus experiences with stress strategies study. Open J Prev Med 2014;4:22-31.

10. Williams EM, Kamen D, Penfield M, et al. Stress intervention and disease in african american lupus patients: the Balancing Lupus Experiences with Stress Strategies (BLESS) Study. Health 2014;6:71-9.

11. Williams EM, Bruner L, Penfield M, et al. Stress and depression in relation to functional health behaviors in African American patients with systemic lupus erythematosus. Rheumatology 2014;2014(Suppl 4): 16.

12. Embuldeniya G, Veinot $\mathrm{P}$, Bell $\mathrm{E}$, et al. The experience and impact of chronic disease peer support interventions: a qualitative synthesis. Patient Educ Couns 2013;92:3-12.

13. Williams EM, Lorig K, Glover S, et al. Intervention to Improve Quality of life for African-AmericaN lupus patients (IQAN): study protocol for a randomized controlled trial of a unique a la carte intervention approach to self-management of lupus in African Americans. BMC Health Serv Res 2016;16:13.

14. Williams EM, Bruner L, Adkins A, et al. I too, am America: a review of research on systemic lupus erythematosus in African-Americans. Lupus Sci Med 2016;3:e000144.

15. Horton R, Peterson MG, Powell S, et al. Users evaluate LupusLine, a telephone peer counseling service. Arthritis Care Res 1997;10:257-63.

16. Tedeschi SK, Guan H, Fine A, et al. Organ-specific systemic lupus erythematosus activity during pregnancy is associated with adverse pregnancy outcomes. Clin Rheumatol 2016;35:1725-32.

17. Kingod N, Cleal B, Wahlberg A, et al. Online peer-to-peer communities in the daily lives of people with chronic illness. Qual Health Res 2017;27:89-99. 
18. Malagon-Maldonado G. Qualitative research in health design. $H E R D$ 2014;7:120-34.

19. O'Brien BC, Harris IB, Beckman TJ, et al. Standards for reporting qualitative research: a synthesis of recommendations. Acad Med 2014;89:1245-51.

20. Sutanto B, Singh-Grewal D, McNeil HP, et al. Experiences and perspectives of adults living with systemic lupus erythematosus: thematic synthesis of qualitative studies. Arthritis Care Res 2013;65:1752-65.

21. Williams EM, Hyer JM, Viswanathan R, et al. Peer-to-peer mentoring for African American women with lupus: a feasibility pilot. Arthritis Care Res 2018;70:908-17.

22. Dooley MA, Aranow C, Ginzler EM. Review of ACR renal criteria in systemic lupus erythematosus. Lupus 2004;13:857-60.

23. Hanly JG. ACR classification criteria for systemic lupus erythematosus: limitations and revisions to neuropsychiatric variables. Lupus 2004;13:861-4.

24. Williams EM, Ortiz K, Zhang J, et al. The systemic lupus erythematosus travel burden survey: baseline data among a South Carolina cohort. BMC Res Notes 2016;9:246

25. Williams EM, Ortiz K, Flournoy-Floyd M, et al. Systemic lupus erythematosus observations of travel burden: a qualitative inquiry. Int $J$ Rheum Dis 2015:18:751-60.

26. Meenan RF, Gertman PM, Mason JH, et al. The arthritis impact measurement scales. Further investigations of a health status measure. Arthritis Rheum 1982;25:1048-53.

27. Stein MJ, Wallston KA, Nicassio PM, et al. Correlates of a clinical classification schema for the arthritis helplessness subscale. Arthritis Rheum 1988;31:876-81.

28. Stein MJ, Wallston KA, Nicassio PM. Factor structure of the arthritis helplessness index. J Rheumatol 1988;15:427-32.

29. Pender NJ, Walker SN, Sechrist KR, et al. Predicting healthpromoting lifestyles in the workplace. Nurs Res 1990;39:326-32.

30. Rosenberg M. Society and the adolescent self-image. Princeton, $\mathrm{NJ}$ : Princeton university press, 1965.

31. Carkhuff RR, Kratochvil D, Friel T. Effects of professional training: communication and discrimination of facilitative conditions. J Couns Psychol 1968;15:68-74

32. Carkhuff RR, Bierman R. Training as a preferred mode of treatment of parents of emotionally disturbed children. J Couns Psychol 1970;17:157-61.

33. Williams EM, Bruner L, Adkins A, et al. CE-02 Peer approaches to lupus self-management (PALS): a novel lupus peer mentorship intervention. Lupus Sci Med 2016;3:A42-A3.

34. Onwuegbuzie A, Leech N. Sampling designs in qualitative research: making the sampling process more public. The Qualitative Report 2007;12:238-54

35. Demaya B, Palm R, Boverie S, Titli A, et al. Multilevel qualitative and numerical optimization of fuzzy controller: Proceedings of $1995 \mathrm{IEEE}$ International Conference on Fuzzy Systems, 1995.
36. Hitt MA, Beamish PW, Jackson SE, et al. Building theoretical and empirical bridges across levels: multilevel research in management Acad Manage J 2007;50:1385-99.

37. Khuwaja RA, Evens MW, Rovick AA, et al. Knowledge representation for an intelligent tutoring system based on a multilevel causal model. In: Frasson C, Gauthier G, McCalla Gl, eds. Intelligent tutoring systems: second international conference, ITS '92 Montréal, Canada, June 10-12 1992 Proceedings. Berlin, Heidelberg: Springer Berlin Heidelberg, 1992:217-24.

38. Braun V, Clarke V. Using thematic analysis in psychology. Qual Res Psychol 2006;3:77-101.

39. Vaismoradi M, Turunen $\mathrm{H}$, Bondas $\mathrm{T}$. Content analysis and thematic analysis: Implications for conducting a qualitative descriptive study. Nurs Health Sci 2013;15:398-405.

40. DeSantis L, Ugarriza DN. The concept of theme as used in qualitative nursing research. West J Nurs Res 2000;22:351-72.

41. Castleberry A. NVivo 10 [software program]. Version 10. QSR International; 2012. Am J Pharm Educ 2014;78:25

42. Boyatzis RE. Transforming qualitative information: thematic analysis and code development: SAGE Publications, 1998:200

43. Barrera M, Castro FG, Strycker LA, et al. Cultural adaptations of behavioral health interventions: a progress report. $J$ Consult Clin Psychol 2013;81:196-205.

44. Williams EM, Egede L, Faith T, et al. Effective self-management interventions for patients with lupus: potential impact of peer mentoring. Am J Med Sci 2017;353:580-92.

45. Williams EM, Penfield M, Kamen D, et al. An intervention to reduce psychosocial and biological indicators of stress in African American lupus patients: the balancing lupus experiences with stress strategies study. Open J Prev Med 2014;4:22-31.

46. MUSC Office of Public Relations. Patients, families with lupus receive support: The Catalyst, 2011.

47. Queen Quet. St. Helena Island, SC2017. 2017. https:// gullahgeecheenation.com/2017/05/18/lupus-awareness-day-thegullahgeechee-way/

48. Waldheim E, Elkan AC, Pettersson S, et al. Health-related quality of life, fatigue and mood in patients with SLE and high levels of pain compared to controls and patients with low levels of pain. Lupus 2013;22:1118-27.

49. Kozora E, Ellison MC, West S. Depression, fatigue, and pain in systemic lupus erythematosus (SLE): relationship to the American College of Rheumatology SLE neuropsychological battery. Arthritis Rheum 2006;55:628-35.

50. Karlen A. Positive sexual effects of chronic illness: case studies of women with lupus (SLE). Sex Disabil 2002;20:191-208.

51. Moses N, Wiggers J, Nicholas C, et al. Prevalence and correlates of perceived unmet needs of people with systemic lupus erythematosus. Patient Educ Couns 2005;57:30-8.

52. Law G, Pope J, Lalani S, et al. Barriers to healthcare in a multiethnic cohort of Systemic Lupus Erythematosus (SLE) patients: patient and physician perceptions. Romanian Journal of Rheumatology 2010;19:12-19. 